Kane Stefan (Orcid ID: 0000-0002-5172-3263)

Ophthalmic sonography and ophthalmic artery Doppler velocimetry in healthy pregnant women: an Australian cohort study

Running title: $\quad$ Ophthalmic sonography in healthy pregnancy

\author{
Authors:

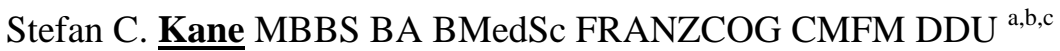 \\ [ORCID 0000-0002-5172-3263]
}

Alicia T. Dennis MBBS PhD MIPH PGDipEcho FANZCA ${ }^{\text {a,de }}$

[ORCID 0000-0002-0709-5722]

Fabrício Da Silva Costa MD MSc PhD FRANZCOG DipFetalMed ${ }^{\text {a,f,g }}$

[ORCID 0000-0002-0765-7780]

Louise H. Kornman MBBS PhD DipFamPln GCertUniTeach FRANZCOG COGU DDU a,b,c [ORCID 0000-0001-7551-3749]

Thomas J. Cade MBBS BMedSc DMedSc FRANZCOG ${ }^{\text {a,b }}$

[ORCID 0000-0003-0804-3032]

Shaun P. Brennecke MBBS BA BMedSc DPhil FRANZCOG ${ }^{\text {a,b }}$

[ORCID 0000-0003-3070-6971]

a. The University of Melbourne, Department of Obstetrics and Gynaecology, The Royal Women's Hospital, Parkville, Victoria, Australia

This is the author manuscript accepted for publication and has undergone full peer review but has not been through the copyediting, typesetting, pagination and proofreading process, which may lead to differences between this version and the Version of Record. Please cite this article as doi: $10.1002 /$ jcu.22735

This article is protected by copyright. All rights reserved. 
b. Pregnancy Research Centre, Department of Maternal Fetal Medicine, The Royal Women's Hospital, Parkville, Victoria, Australia

c. Ultrasound Service, Pauline Gandel Women’s Imaging Centre, The Royal Women's Hospital, Parkville, Victoria, Australia

d. Department of Anaesthesia, The Royal Women's Hospital, Parkville, Victoria, Australia

e. The University of Melbourne, Department of Medicine \& Radiology and Department of Pharmacology \& Therapeutics, Parkville, Victoria, Australia

f. Monash University, Department of Obstetrics and Gynaecology, Clayton, Victoria, Australia

g. Departamento de Ginecologia e Obstetricia, Hospital das Clinicas da Faculdade de Medicina de Ribeirão Preto da Universidade de São Paulo, Ribeirão Preto, Estado de São Paulo, Brazil

\section{Corresponding Author:}

Dr Stefan C. Kane

Department of Maternal Fetal Medicine, The Royal Women’s Hospital

Locked Bag 300, Parkville VIC 3052, Australia

Phone: +61 $413714322 \quad$ Fax: +61 $383452139 \quad$ Email: $\underline{\text { Stefan.Kane@thewomens.org.au }}$

\section{Conflicts of Interest:}

The authors have no competing or conflicting interests to declare.

\section{Acknowledgements:}


The authors acknowledge with gratitude the assistance of Ms Adrienne White in recruiting participants to this study. SCK is supported by an Australian Government Research Training Program Scholarship, and by a Postgraduate Scholarship from the Australian National Health and Medical Research Council. His $\mathrm{PhD}$ project is supported by grants from the Australasian Society for Ultrasound in Medicine, and from the Research Foundation of the Royal Australian and New Zealand College of Obstetricians and Gynaecologists.

\title{
Ophthalmic sonography and ophthalmic artery Doppler velocimetry in healthy pregnant women: an Australian cohort study
}

\begin{abstract}
Purpose

Maternal ocular sonography offers a window into cerebrovascular and intracranial pressure changes in pregnancy. This study aimed to determine the Doppler velocimetric variables of the ophthalmic artery, and the mean diameter of the optic nerve sheath diameter, in an Australian cohort of healthy pregnant women.
\end{abstract}

\section{Methods}

Prospective observational cohort study of healthy women with uncomplicated singleton pregnancies in the third trimester attending a tertiary maternity service. A single antenatal ultrasonographic examination was 
performed on all participants, with a postnatal examination performed on a subgroup with uncomplicated deliveries.

\section{Results}

50 women were examined at a mean gestation of 35 weeks. The mean \pm SD Doppler variables in the ophthalmic artery were: peak systolic velocity $41.89 \pm 13.13 \mathrm{~cm} / \mathrm{s}$, second peak velocity $20.63 \pm 8.97$ $\mathrm{cm} / \mathrm{s}$, end diastolic velocity $9.29 \pm 5.13 \mathrm{~cm} / \mathrm{s}$, pulsatility index $1.97 \pm 0.53$, resistive index $0.78 \pm 0.07$, peak ratio (second peak velocity / peak systolic velocity) $0.49 \pm 0.12$, while the mean optic nerve sheath diameter was $4.34 \pm 0.4 \mathrm{~mm}$. None of these variables had a demonstrable relationship with gestation or mean arterial pressure, nor did the sheath diameter have a relationship with any of the Doppler variables.

\section{Conclusion}

The ocular sonographic variables observed in this population are similar to those reported in other cohorts. No clear relationship could be identified in this cohort between ophthalmic artery Doppler variables and the optic nerve sheath diameter, and between each of these variables and gestation or mean arterial pressure.

\section{KEYWORDS (MeSH terms)}

Ophthalmic artery ultrasonography

Optic nerve

Doppler ultrasonography

Pregnancy 
Pre-eclampsia

Hypertension, pregnancy-induced 


\section{INTRODUCTION}

Hypertensive disorders of pregnancy, including pre-eclampsia, complicate around 6-8\% of pregnancies worldwide, ${ }^{1}$ and remain a leading cause of maternal morbidity and mortality. ${ }^{2,3}$ A significant proportion of the adverse maternal sequelae of these conditions is mediated by their neurological complications, such as eclampsia or intracerebral haemorrhage. ${ }^{4}$ Therapies such as antihypertensive medication and magnesium sulphate have a proven role in reducing the incidence of these outcomes, ${ }^{5}$ but their precise intracranial mechanism of action is yet to be determined, and selecting which patients to treat with what agent and regimen remains clinically challenging. ${ }^{6}$

Point-of-care ultrasound has an evolving utility in a wide range of clinical settings, as it is a safe, well tolerated, and relatively low cost means of assessing patients in real-time at the bedside. ${ }^{7,8}$ Trans-cranial Doppler interrogation of the maternal middle cerebral artery has been employed to assess velocimetric changes induced in this larger-calibre intracranial vessel by pre-eclampsia ${ }^{9}$ and its treatments, ${ }^{10}$ although this may not be the level of arterial branching at which pre-eclampsia exerts its adverse neurological effects. Trans-orbital ophthalmic ultrasonography offers an alternative window into the intracranial environment, through assessment of both the ophthalmic artery and the optic nerve sheath.

The ophthalmic artery is embryologically and functionally similar to the small calibre intracerebral vessels in which the changes responsible for the neurological complications of pre-eclampsia are thought to occur. ${ }^{9}$ As these intracerebral vessels are relatively inaccessible to ultrasound, Doppler velocimetry of the ophthalmic artery permits a surrogate assessment of cerebral haemodynamics. The spectral waveform of 
the ophthalmic artery is dicrotic (Fig. 1), with two systolic peaks each followed by a 'notch', the second of which represents closure of the aortic valve. ${ }^{11}$ Standard measures of impedance and resistance - the pulsatility and resistive indices - can be calculated from this waveform, in addition to the 'peak ratio', which is the ratio of the second systolic peak to the first. This latter measure has been found to be significantly higher in women with pre-eclampsia, ${ }^{12}$ and may represent the most sensitive indicator of the cerebrovascular changes that occur in this condition.

$<$ Figure 1 $>$

The optic nerve sheath can be clearly visualised behind the eyeball on ophthalmic sonography (Fig. 2). ${ }^{13}$ The optic nerve - the second cranial nerve - is in direct continuity with the brain, and so the diameter of its sheath provides an indirect measure of intracranial pressure, ${ }^{14}$ increases in which are a feature of the cerebral oedema that can accompany pre-eclampsia ${ }^{15}$ and other hypertensive states. ${ }^{16}$

$<$ Figure 2>

There is an evolving body of evidence regarding the potential utility of both the Doppler variables of the ophthalmic artery ${ }^{17}$ and the optic nerve sheath diameter ${ }^{15,18}$ in assessing patients with pre-eclampsia, to improve our understanding of the cerebral effects of this condition and its treatments in real time. The advent of high-quality portable ultrasound machines invites the prospect of this point-of-care imaging modality being used to individualise the care of women with pre-eclampsia, with a view to minimising the costs and consequences of both over- and under-treatment. 
As a precursor to further research into these applications, the aims of the present study were:

- To determine the Doppler velocimetric variables of the ophthalmic artery, and the mean diameter of the optic nerve sheath, in an Australian cohort of healthy pregnant women;

- To establish the relationship in this cohort between ophthalmic artery Doppler variables and the optic nerve sheath diameter, and between each of these variables and gestation and mean arterial pressure;

- To compare pre- and post-birth ophthalmic artery Doppler variables and optic nerve sheath diameters in this cohort; and

- To determine the post hoc inter- and intra-reader reliability on stored images for the sonographic variables that could not be derived automatically, namely the second peak velocity of the ophthalmic artery, and the optic nerve sheath diameter.

\section{PATIENTS AND METHODS}

This prospective observational cross-sectional cohort study was undertaken in a public tertiary maternity service in which over 7500 babies are born each year, and was conducted in accordance with the STROBE statement on the performance of observational studies. ${ }^{19}$ Participants were recruited randomly from lowrisk women attending the general antenatal clinics for routine review in the third trimester, with recruitment occurring between April 2015 and June 2016.

Women were eligible to participate if they had an uncomplicated singleton pregnancy at greater than 27 weeks' gestation, had no pre-existing medical conditions, were not taking any medications apart from 
pregnancy-related vitamins or minerals, did not smoke tobacco or use illicit drugs, and did not require the assistance of an interpreter. Women were ineligible if they had any active pre-existing medical conditions, had developed any pregnancy-specific complications such as gestational diabetes, were pregnant with twins or a higher-order multiple gestation, or were unable to comprehend a plain English language explanation of the study for any reason. Written informed consent was obtained from each participant, with the study having been approved by the institutional Human Research Ethics Committee (HREC Study 13/29).

Following consent, eligibility was confirmed and baseline demographic and clinical data were obtained by taking a focussed patient history, and reviewing the medical record. A study record number was allocated to each patient, to permit post-hoc anonymisation of the data. Each participant was invited to rest quietly in a private room for ten minutes prior to the examination, lying on a bed in the left lateral position to avoid aortocaval compression.

Examinations commenced with the patient turning to lie in a semi-recumbent position, with the back of the bed angled at 45 degrees. Blood pressure readings were taken from both arms using a 3BTO-A blood pressure monitor (Microlife, Taipei, Taiwan), ${ }^{20}$ from which the mean arterial pressure was derived.

All ultrasound examinations were performed by a single experienced investigator using a Logiq e portable ultrasound machine and a L4-12t broadband linear transducer (GE Healthcare, Fairfield, Connecticut, USA). The investigator stood at the right side of the bed, facing the patient, and as unilateral examination 
has previously been validated, ${ }^{21}$ only the right eye was insonated. All images were stored on the machine in DICOM format, to permit later reanalysis.

Examination of the ophthalmic artery was performed in accordance with established protocols: ${ }^{22}$

- The transducer was applied directly to the closed eyelid following application of a drop of sterile gel

- The transducer was positioned horizontally over the upper aspect of the eyeball

- Using colour Doppler, the ophthalmic artery was identified by its direction of flow (toward the probe) and pulsatility

- Pulsed wave Doppler was then applied, with the sample volume placed around $15 \mathrm{~mm}$ behind the optic disc, medial to the optic nerve

- $\quad$ The sample volume was set at $2 \mathrm{~mm}$

- A standard angle correction of 30 degrees was employed and then adjusted according to the anatomy of the vessel under examination, to optimise the velocities obtained

- The high-pass filter was set to its minimum value

- The PRF (pulse repetition frequency) was adapted as necessary to achieve an optimal spectral waveform

- Three consistent cardiac cycles were obtained and stored electronically.

Following Doppler interrogation, B-mode imaging alone was employed to obtain a still image of the optic nerve. The nerve was assessed in two planes - transverse and sagittal, the latter requiring rotation of the probe by 90 degrees. ${ }^{23}$ At all times, the ultrasound machine settings maintained compliance with the 
standards published by the safety group of the British Medical Ultrasound Society, with a thermal index (TIS) of $<1.0$, and a mechanical index (MI) of $<0.3 .^{24}$

Patients were followed up immediately after delivery, to confirm that their pregnancies had remained uncomplicated by hypertension or other obstetric concerns, such as gestational diabetes or fetal growth restriction. Maternal and neonatal outcome data were collected from the medical record. Those participants whose pregnancies had resulted in vaginal births uncomplicated by significant perineal injury or postpartum haemorrhage were invited to undergo repeat ophthalmic ultrasound examination, in the same manner as described above.

All sonographic data were derived from post-hoc analysis of the stored DICOM images, and were entered into an Excel spreadsheet (Microsoft Corporation, Redmond, Washington, USA). Ophthalmic artery Doppler variables were derived from the average of three consecutive waveforms. The values recorded for the following variables were those calculated automatically by the ultrasound machine based on the Doppler waveform (maximum velocities envelope):

- $\quad$ peak systolic velocity (PSV)

- $\quad$ end-diastolic velocity (EDV)

- $\quad$ time-averaged maximum velocity $(\mathrm{TAMaxV})=$ time average of the maximum velocities over the included waveforms

- $\quad$ pulsatility index $(\mathrm{PI})=\frac{\text { peak systolic velocity }- \text { end-diastolic velocity }}{\text { mean velocity }}$

- $\quad$ resistive index $(\mathrm{RI})=\frac{\text { peak systolic velocity }- \text { end-diastolic velocity }}{\text { peak systolic velocity }}$ 
Manual calculations were all performed in the first instance by the primary investigator. The second systolic peak velocity was recorded as the average of the values determined manually using an electronic caliper on each of the same three waveforms. The peak ratio was calculated by dividing the second peak velocity by the peak systolic velocity. The optic nerve sheath diameter was obtained by placing electronic calipers across the optic nerve sheath $3 \mathrm{~mm}$ behind the globe, perpendicular to the optic nerve, with the value recorded being the average of the diameters in two planes.

To facilitate assessment of post hoc intra- and inter-reader reliability, those variables requiring manual assessment on stored images - the second peak velocity of the ophthalmic artery, and the optic nerve sheath diameter - were assessed again on separate occasions in a blinded fashion by the primary investigator, and by another experienced sonologist. For intra-reader measurements, the primary investigator reassessed all images two months after the first assessment.

\section{Statistical considerations}

The cohort size was a sample of convenience of 50 participants, with planned recruitment in excess of this to account for participants who would later develop complications that would render them ineligible. Descriptive statistics were employed in the presentation of the data, with normally-distributed values presented as means \pm SD, and non-normally distributed data as medians and IQR. The relationship between antenatal ophthalmic artery Doppler variables and the optic nerve sheath diameter, and between each of these variables and gestation and antenatal mean arterial pressure, was assessed using a generalised linear model with calculation of the Wald statistic. Comparisons for ophthalmic sonographic variables from antenatal and postnatal examinations were performed using paired t-tests. Mean 
differences, 95\% confidence intervals (CI), and two-sided P values are given with a significance level alpha of 0.05. Post hoc inter- and intra-reader reliability of stored images of the ophthalmic artery Doppler waveform (for assessment of the second peak velocity) and the optic nerve sheath (for assessment of its diameter) was assessed by calculation of correlation coefficients $(r),{ }^{25}$ with a coefficient of $0-0.2$ deemed to represent poor agreement, $0.3-0.4$ fair agreement, $0.5-0.6$ moderate agreement, $0.7-0.8$ strong agreement, and $>0.8$ optimal agreement. ${ }^{26}$ Statistical analyses were performed using both Excel (2016, Microsoft Corporation, Redmond, Washington, USA) and STATA release 15 (2017, StataCorp, College Station, Texas, USA).

\section{RESULTS}

Between April 2015 and June 2016, fifty-six women consented to participate in this study, yielding a final cohort of fifty women whose pregnancies remained uncomplicated and resulted in a term birth of a normally-grown infant. Of these, twenty-one had uncomplicated vaginal births and were available for postnatal assessment. The recruitment pathway is outlined in Figure 3.

$<$ Figure 3>

The baseline characteristics of participants are summarised in table 1.

$<$ Table $1>$ 
The outcomes of antenatal ophthalmic sonography in this cohort are summarised in table 2 . The mean gestation at the time of examination equated to 35 completed weeks (range 27 weeks 2 days to 40 weeks 6 days).

$<$ Table 2>

\begin{abstract}
A generalised linear model was employed to examine the relationship between gestation, mean arterial pressure, and various sonographic variables, as outlined in table 3. In no instance was there evidence to reject the null hypothesis (that there is no relationship between the two variables). Scatter plots with trendlines for each relationship are provided as a supplementary appendix.
\end{abstract}

$<$ Table 3>

The mean (SD) gestation at delivery for the entire cohort was $282.78 \pm 7.77$ days (40 weeks and 2 days), with a mean (SD) blood loss at delivery of $415 \pm 271 \mathrm{~mL}$. Twenty-eight of the women (56\%) had an unassisted vaginal birth, while eighteen (36\%) had an instrumental delivery, and four (8\%) were delivered by caesarean section. The mean (SD) birthweight was $3702.9 \pm 443.2$ grams, and there was a preponderance of female infants (60\%). The median (IQR) Apgar score at five minutes was 9 (9-9). No infant was admitted to the neonatal nursery.

The outcomes of postnatal ophthalmic sonography in the sub-cohort of twenty-one women who had uncomplicated vaginal births and were available for assessment are summarised in table 4 . There were 
statistically significant differences in the mean end diastolic velocity, time-averaged maximum velocity, and the pulsatility and resistive indices when compared to values obtained antenatally, with differences in the other variables being non-significant (Table 4).

\section{$<$ Table 4>}

\section{Measures of inter- and intra-reader reliability}

A total of 74 stored discrete ophthalmic sonographic examinations were available for post hoc calculation of the inter- and intra-reader reliability of those variables not derived automatically by the ultrasound machine: the second peak velocity of the ophthalmic artery Doppler waveform, and the optic nerve sheath diameter (Table 5).

\section{$<$ Table 5>}

\section{DISCUSSION}

This is the first study to report on Doppler variables in the ophthalmic artery and the sonographic dimensions of the optic nerve sheath diameter in an Australian cohort of healthy pregnant women with uncomplicated term births of well-grown infants. The pregnancy outcomes reported herein confirm this characterisation of the final cohort, and align with Australian population norms. ${ }^{27,28}$ 
The mean ophthalmic artery Doppler variables identified in this study are broadly in keeping with the reference ranges derived in healthy pregnant populations elsewhere. ${ }^{21,29-38}$ A summary of the findings of these studies which report the means of key Doppler variables is presented in table 6, alongside the findings of the present study for comparison.

$<$ Table 6>

The absence of a clear relationship between ophthalmic artery Doppler variables and advancing gestation in this study is both biologically plausible and in keeping with the findings of a number of earlier studies. ${ }^{30,34,44,47}$ In contrast, other series ${ }^{21,31,32,48}$ have found that Doppler indices do relate to gestation, with measures of resistance (the pulsatility index or resistive index) tending to decrease with advancing gestational age. Two of these latter studies -Mackenzie et al. ${ }^{31}$ and Ohno et al. ${ }^{32}$ - were performed in the 1990s, when Doppler ultrasound technology was still in the relatively early stages of clinical development. Another - Barbosa ${ }^{48}$ - has only been published in a book in Portuguese and could not be obtained for detailed analysis. The most recent of these studies - Corrêa-Silva et al. ${ }^{21}$ - was longitudinal in nature: 63 healthy pregnant women were examined every two weeks, revealing an apparent decline in measures of resistance as gestation advanced. Conversely, the two largest and most recent studies of ophthalmic artery Doppler variables in healthy pregnancy - de Oliveira et al. ${ }^{30}(\mathrm{n}=289)$ and Carneiro et al. ${ }^{47}(\mathrm{n}=276)$ - were cross-sectional in design, i.e. participants were recruited at a range of gestations, and only examined once. Neither found a clear correlation between gestation and any of the ophthalmic artery Doppler variables, a finding whose validity may be enhanced by their cross-sectional design, which has been suggested to be superior in determining relationships with gestational age. ${ }^{49}$ 
Interestingly, all studies that assessed the correlation between ophthalmic artery Doppler indices and gestation in healthy pregnancies found the peak ratio (the ratio of the second peak velocity to the first peak velocity) to remain relatively constant. Both of these peak velocities are thought to occur in systole, with the latter followed by a 'notch' that reflects closure of the aortic valve. ${ }^{11}$

Relatively few studies have assessed the relationship between mean arterial pressure (MAP) and ophthalmic artery Doppler variables. Guthoff et al. ${ }^{50}$ found no correlation between the two in healthy nonpregnant adults, while Mackenzie et al. ${ }^{31}$ found a weak negative correlation that was statistically insignificant in a population of healthy pregnant women. In contrast, Belfort et al. ${ }^{43}$ observed a decrease in the ophthalmic artery resistive index with increasing MAP in a sample of 24 healthy pregnant women. Similarly, Hata et al. ${ }^{44}$ described a close inverse correlation between MAP and the ophthalmic artery pulsatility index, but this was in a population that included normotensive gravidas as well as women with gestational hypertension and pre-eclampsia - conditions that may independently have an impact on ophthalmic artery velocimetry. If the ophthalmic artery is truly representative of the smaller calibre intracerebral vessels, and if velocimetry of the former is a reliable measure of the haemodynamics of the latter, a lack of correlation between MAP and ophthalmic artery Doppler variables is in keeping with the principles of physiological homeostasis. ${ }^{51,52}$

There are few published data with which to compare the present study's findings with respect to the optic nerve sheath diameter. Singh et al. ${ }^{18}$ identified a mean diameter of $4.7 \pm 0.46 \mathrm{~mm}$ in a population of 25 healthy pregnant women at an average gestation of 36 weeks. In a sample of the same size, at a mean gestation of 34 weeks and 5 days, Dubost et al. ${ }^{15}$ found the average diameter to be $4.5 \mathrm{~mm}$ (95\% CI 4.3 - 
$4.8 \mathrm{~mm}$ ), while Brzan Simenc et al. ${ }^{53}$ identified a mean diameter of $4.5 \mathrm{~mm}$ in a group of 30 healthy pregnant women at an average of 38 weeks and 3 days. None of these studies assessed the relationship between MAP, gestational age or ophthalmic artery Doppler variables and the optic nerve sheath diameter. The present study of fifty healthy pregnant women is larger and covers a broader gestational range than earlier series, and is the first to investigate these relationships. Again, that no correlation could be identified is not unexpected, in keeping with principles of homeostasis. ${ }^{54}$

Significant haemodynamic changes occur immediately and in the days following delivery. The relief of inferior vena cava compression by the gravid uterus, coupled with the autotransfusion of blood back into the maternal circulation from the now-contracted uterus, leads to an immediate increase in cardiac output by $60-80 \%$, which falls to pre-labour levels by one hour post-partum, and to baseline levels at two weeks after delivery. ${ }^{55}$ Blood pressure rises to a peak at 3-6 days postpartum, then normalises. The present study found no statistically significant difference between the antenatal and postnatal cohorts in the mean arterial pressure or the two peak systolic velocities (and thus the peak ratio) of the ophthalmic artery. The only changes of significance were a reduction in the end-diastolic ophthalmic artery velocity, and consequently a reduced time-averaged maximum velocity and increased pulsatility and resistive indices. This is a novel finding, as although other authors have compared postnatal ophthalmic artery Doppler variables in a cohort of previously pre-eclamptic women with normotensive controls, ${ }^{56,57}$ this is the first study to observe the impact of delivery within the same cohort. The apparent increase in vascular resistance may reflect a healthy cerebrovascular response to the normal changes in cardiac output after delivery, as homeostasis is re-established through a rise in systemic vascular resistance to pre-pregnancy 
levels. The lack of postpartum change in the mean optic nerve sheath diameter in this and another study ${ }^{15}$ is not surprising, as healthy pregnancy is not thought to alter the intracranial pressure. ${ }^{58}$

Inter- and intra-observer reliability relates to the reproducibility of the examination itself, whereas interand intra-reader reliability relates to the post hoc interpretation of stored ultrasound images. The former has been found by other authors to be high, for both Doppler variables of the ophthalmic artery ${ }^{21,59}$ and dimensions of the optic nerve sheath. ${ }^{53,60,61}$ It was not feasible to assess observer reliability in the present study. Instead, it has focused on the post hoc reproducibility, or precision, of those measurements not performed automatically by the ultrasound machine. This reproducibility is considered an important means of addressing potential operator bias, given that this was a single operator study in which blinding of other variables, such as blood pressure, during the examination process was not possible. Using stored images, the post hoc inter- and intra-reader correlation coefficients for the second peak velocity of the ophthalmic artery were at the upper end of the 'optimal' range, almost achieving unity. The degree of agreement for post hoc measurements of the optic nerve sheath diameter was slightly lower, but still clinically acceptable, with an intra-reader correlation coefficient at the lower end of the 'optimal' range, and an inter-reader coefficient at the upper end of the 'strong' range. This is not unexpected, given the technical challenges associated with this assessment, ${ }^{23}$ and is in keeping with the findings of earlier studies. $^{62}$

\section{Strengths and Limitations}

The strengths of this study include its carefully characterised population of healthy pregnant women who were confirmed to have uncomplicated pregnancy outcomes, its use of a single experienced sonologist and 
protocolised technique for all examinations, and its inclusion of postnatal assessments that permitted observations regarding the within-cohort impact of delivery. It is the first study to combine assessments of the optic nerve sheath diameter and Doppler variables of the ophthalmic artery, and to evaluate the relationship between the two. The validity of its findings is enhanced by the reassuring measures of interand intra-reader reliability. As with any study, there are some limitations that need to be considered in the interpretation of its results, including the relatively small sample size (especially that of the postnatal subcohort, as many women were lost to follow up due to discharge from hospital within 24 hours of having given birth), and the potential impact of unrecognised confounding factors, again particularly in the postnatal examinations. Furthermore, it was not possible to assess inter- or intra-observer reliability.

\section{Conclusions}

The Doppler velocimetric variables of the ophthalmic artery, and the mean diameter of the optic nerve sheath diameter, in an Australian cohort of healthy pregnant women are broadly comparable to those established in other populations. No clear relationship could be identified in this cohort between ophthalmic artery Doppler variables and the optic nerve sheath diameter, and between each of these variables and gestation or mean arterial pressure. There appears to be an increase in cerebral vascular resistance post-partum, mediated by lower end-diastolic velocities rather than changes in systole, while no postnatal change in intracranial pressure was evident.

\section{REFERENCES}

1. Gillon TER, Pels A, von Dadelszen P, et al. Hypertensive Disorders of Pregnancy: A Systematic Review of International Clinical Practice Guidelines. PLoS One 2014;9:e113715. 
2. Mol BWJ, Roberts CT, Thangaratinam S, et al. Pre-eclampsia. Lancet 2016;387:999.

3. Dennis AT. Science, Sex and Society - why maternal mortality is still a global health issue. Anaesthesia 2016;71:1003.

4. Zeeman GG. Neurologic complications of pre-eclampsia. Semin Perinatol 2009;33:166.

5. Brown MA, Magee LA, Kenny LC, et al. Hypertensive Disorders of Pregnancy: ISSHP Classification, Diagnosis, and Management Recommendations for International Practice. Hypertension 2018;72:24.

6. Kane SC, Dennis A, da Silva Costa F, et al. Contemporary Clinical Management of the Cerebral Complications of Preeclampsia. Obstet Gynecol Int 2013;2013:985606.

7. Smallwood N, Dachsel M. Point-of-care ultrasound (POCUS): unnecessary gadgetry or evidencebased medicine? Clin Med (Lond.) 2018;18:219.

8. Dennis AT. Transthoracic echocardiography in obstetric anaesthesia and obstetric critical illness. Int J Obstet Anesth 2011;20:160.

9. Belfort MA, Giannina G, Herd JA. Transcranial and orbital Doppler ultrasound in normal pregnancy and preeclampsia. Clin Obstet Gynecol 1999;42:479.

10. Belfort MA, Tooke-Miller C, Allen JC, Jr., et al. Labetalol decreases cerebral perfusion pressure without negatively affecting cerebral blood flow in hypertensive gravidas. Hypertens Pregnancy 2002;21:185.

11. Williamson TH, Harris A. Color Doppler ultrasound imaging of the eye and orbit. Surv Ophthalmol 1996;40:255.

12. de Oliveira CA, de Sa RA, Velarde LG, et al. Changes in ophthalmic artery Doppler indices in hypertensive disorders during pregnancy. J Ultrasound Med 2013;32:609.

13. Rollins M, Flood P. Imaging intracranial pressure: an introduction to ultrasonography of the optic nerve sheath. Anesthesiology 2012;116:983.

14. Robba C, Santori G, Czosnyka M, et al. Optic nerve sheath diameter measured sonographically as non-invasive estimator of intracranial pressure: a systematic review and meta-analysis. Intensive Care Med 2018;44:1284.

15. Dubost C, Le Gouez A, Jouffroy V, et al. Optic nerve sheath diameter used as ultrasonographic assessment of the incidence of raised intracranial pressure in preeclampsia: a pilot study.

Anesthesiology 2012;116:1066.

16. Lochner P, Mader C, Nardone R, et al. Usefulness of ultrasonography in posterior reversible encephalopathy syndrome. Neurol Sci 2014;35:475.

17. Kane SC, Brennecke SP, da Silva Costa F. Ophthalmic artery Doppler analysis: a window into the cerebrovasculature of women with pre-eclampsia. Ultrasound Obstet Gynecol 2017;49:15.

18. Singh SK, Bhatia K. Ultrasonographic Optic Nerve Sheath Diameter as a Surrogate Measure of Raised Intracranial Pressure in Severe Pregnancy-induced Hypertension Patients. Anesth Essays Res 2018;12:42.

19. von Elm E, Altman DG, Egger M, et al. The Strengthening the Reporting of Observational Studies in Epidemiology (STROBE) statement: guidelines for reporting observational studies. Lancet 2007;370:1453.

20. Reinders A, Cuckson AC, Lee JT, et al. An accurate automated blood pressure device for use in pregnancy and pre-eclampsia: the Microlife 3BTO-A. BJOG 2005;112:915. 
21. Correa-Silva EP, Surita FG, Barbieri C, et al. Reference values for Doppler velocimetry of the ophthalmic and central retinal arteries in low-risk pregnancy. Int J Gynaecol Obstet 2012;117:251.

22. Kane SC, Khong SL, da Silva Costa F. Diagnostic Imaging: Ultrasound. In Pre-eclampsia 2018 (pp. 1-8). Humana Press, New York, NY.

23. Dubost C, Geeraerts T. Possible pitfalls when measuring the optic nerve sheath with sonography. J Surg Res 2012;173:e43.

24. British Medical Ultrasound Society. Guidelines for the safe use of diagnostic ultrasound equipment. Ultrasound 2010;18:52.

25. Bunce C. Correlation, agreement, and Bland-Altman analysis: statistical analysis of method comparison studies. Am J Ophthalmol 2009;148:4.

26. Hassen GW, Bruck I, Donahue J, et al. Accuracy of Optic Nerve Sheath Diameter Measurement by Emergency Physicians Using Bedside Ultrasound. J Emerg Med 2015;48:450.

27. Dobbins TA, Sullivan EA, Roberts $\mathrm{CL}$, et al. Australian national birthweight percentiles by sex and gestational age, 1998-2007. Med J Aust 2012;197:291.

28. Australian Institute of Health and Welfare., National Perinatal Statistics Unit. Australia's mothers and babies 2016. Sydney: AIHW National Perinatal Statistics Unit; 2016.

29. Carneiro RS, Sass N, Diniz AL, et al. Ophthalmic artery Doppler velocimetry in healthy pregnancy. Int J Gynaecol Obstet 2008;100:211.

30. de Oliveira CA, de Sa RA, Velarde LG, et al. Doppler velocimetry of the ophthalmic artery in normal pregnancy: reference values. J Ultrasound Med 2009;28:563.

31. MacKenzie F, De Vermette R, Nimrod C, et al. Doppler sonographic studies on the ophthalmic and central retinal arteries in the gravid woman. J Ultrasound Med 1995;14:643.

32. Ohno Y, Kawai M, Wakahara Y, et al. Ophthalmic artery velocimetry in normotensive and preeclamptic women with or without photophobia. Obstet Gynecol 1999;94:361.

33. Ayaz T, Akansel G, Hayirlioglu A, et al. Ophthalmic artery color Doppler ultrasonography in mildto-moderate preeclampsia. Eur J Radiol 2003;46:244.

34. Diniz AL, Moron AF, dos Santos MC, et al. Ophthalmic artery Doppler as a measure of severe preeclampsia. Int J Gynaecol Obstet 2008;100:216.

35. Hata T, Hata K, Moritake K. Maternal ophthalmic artery Doppler velocimetry in normotensive pregnancies and pregnancies complicated by hypertensive disorders. Am J Obstet Gynecol Surv 1997;177:174.

36. Hata $\mathrm{T}$, Senoh $\mathrm{D}$, Hata $\mathrm{K}$, et al. Ophthalmic artery velocimetry in pregnant women. Lancet 1992;340:182.

37. Nakatsuka M, Takata M, Tada K, et al. Effect of a nitric oxide donor on the ophthalmic artery flow velocity waveform in preeclamptic women. J Ultrasound Med 2002;21:309.

38. Takata M, Nakatsuka M, Kudo T. Differential blood flow in uterine, ophthalmic, and brachial arteries of preeclamptic women. Obstet Gynecol 2002;100:931.

39. Belfort MA, Saade GR, Snabes M, et al. Hormonal status affects the reactivity of the cerebral vasculature. Am J Obstet Gynecol 1995;172:1273.

40. Hata $T$, Hashimoto $M$, Senoh D, et al. Effect of dehydroepiandrosterone sulfate on ophthalmic artery flow velocity waveforms in full-term pregnant women. Am J Perinatol 1995;12:135. 
41. Hata $\mathrm{T}$, Yanagihara $\mathrm{T}$, Tanaka $\mathrm{H}$, et al. Maternal ophthalmic artery doppler velocimetry in type 1 diabetes during pregnancy. Hum Reprod (Oxford, England) 2000;15:222.

42. Hata T, Miyazaki K. Maternal ophthalmic artery Doppler velocimetry in normotensive pregnancies with small-for-gestational-age infants. Ultrasound Obstet Gynecol 1998;11:328.

43. Belfort MA, Saade GR, Grunewald C, et al. Effects of blood pressure on orbital and middle cerebral artery resistances in healthy pregnant women and women with preeclampsia. Am J Obstet Gynecol 1999;180:601.

44. Hata T, Hata K, Moritake K. Maternal ophthalmic artery Doppler velocimetry in normotensive pregnancies and pregnancies complicated by hypertensive disorders. Am J Obstet Gynecol 1997;177:174.

45. Diniz AL, Moron AF, Santos MC, et al. Ophthalmic artery Doppler as a measure of severe preeclampsia. Int J Gynecol Obstet 2008;100.

46. Melo NA, Araujo Junior E, Helfer TM, et al. Assessment of maternal Doppler parameters of ophthalmic artery in fetuses with growth restriction in the third trimester of pregnancy: A casecontrol study. J Obstet Gynaecol Res 2015;41:1330.

47. Carneiro RS, Sass N, Diniz AL, et al. Ophthalmic artery Doppler velocimetry in healthy pregnancy. Int J Gynaecol Obstet 2008;100:211.

48. Barbosa AS. Estudo da Associação entre as Manifestações Oftálmicas da Pré-eclâmpsia Grave e os Parâmetros de Fluxo Sanguíneo das Artérias Oftálmica e Central da Retina ao Ecodoppler Ocular. Belo Horizonte: Tese (Doutorado), Universidade Federal de Minas Gerais; 2004.

49. Napolitano R, Dhami J, Ohuma EO, et al. Pregnancy dating by fetal crown-rump length: a systematic review of charts. BJOG 2014;121:556.

50. Guthoff RF, Berger RW, Winkler P, et al. Doppler ultrasonography of the ophthalmic and central retinal vessels. Arch Ophthalmol 1991;109:532.

51. Bill A. Blood circulation and fluid dynamics in the eye. Physiol Rev 1975;55:383.

52. van Veen TR, Panerai RB, Haeri S, et al. Cerebral autoregulation in normal pregnancy and preeclampsia. Obstet Gynecol 2013;122:1064.

53. Brzan Simenc G, Ambrozic J, Prokselj K, et al. Ocular ultrasonography for diagnosing increased intracranial pressure in patients with severe preeclampsia. Int J Obstet Anesth 2018.

54. Nemoto EM. Dynamics of cerebral venous and intracranial pressures. Acta Neurochir Suppl 2006;96:435.

55. Nelson-Piercy C. Handbook of obstetric medicine. CRC press; 2015 Apr 8.

56. Alves Borges JH, Goes DA, de Araújo LB, et al. Prospective study of the hemodynamic behavior of ophthalmic arteries in postpartum preeclamptic women: A doppler evaluation. Hypertens Pregnancy 2016;35:100.

57. Giannina G, Belfort MA, Cruz AL, et al. Persistent cerebrovascular changes in postpartum preeclamptic women: a Doppler evaluation. Am J Obstet Gynecol 1997;177:1213.

58. Anson JA, Vaida S, Giampetro DM, et al. Anesthetic management of labor and delivery in patients with elevated intracranial pressure. Int J Obstet Anesth 2015;24:147.

59. Matthiessen ET, Zeitz O, Richard G, et al. Reproducibility of blood flow velocity measurements using colour decoded Doppler imaging. Eye (Lond.) 2004;18:400. 
60. Bauerle J, Schuchardt F, Schroeder L, et al. Reproducibility and accuracy of optic nerve sheath diameter assessment using ultrasound compared to magnetic resonance imaging. BMC Neurol 2013;13:187.

61. Lochner P, Coppo L, Cantello R, et al. Intra- and interobserver reliability of transorbital sonographic assessment of the optic nerve sheath diameter and optic nerve diameter in healthy adults. J Ultrasound 2016;19:41.

62. Oberfoell S, Murphy D, French A, et al. Inter-rater Reliability of Sonographic Optic Nerve Sheath Diameter Measurements by Emergency Medicine Physicians. J Ultrasound Med 2017;36:1579.

\section{FIGURE LEGENDS}

Figure 1: Ophthalmic artery sonography and Doppler spectral waveform. P1 = peak systolic velocity, P2 = second peak velocity, EDV = end diastolic velocity.

Figure 2: Optic nerve sheath diameter (ONSD) on transorbital sonography.

Figure 3: Recruitment pathway

\begin{tabular}{|l|c|}
\hline & Mean \pm SD or Median (IQR) \\
\hline Age (years) & $32.4 \pm 4.15$ \\
\hline Gravidity & $2(1,2)$ \\
\hline Parity & $0(0,1)$ \\
\hline BMI $\left(\mathrm{kg} / \mathrm{m}^{2}\right)$ & $24.42 \pm 3.45$ \\
\hline
\end{tabular}

Table 1: Baseline characteristics 


\begin{tabular}{|l|c|}
\hline & $\begin{array}{c}\text { Mean } \pm \text { SD } \\
\text { (n = 50) }\end{array}$ \\
\hline Gestation at time of examination (days) & $245.24 \pm 23.86$ \\
\hline Mean arterial pressure (mmHg) $\quad$ Ophthalmic artery Doppler variables \\
\hline \multicolumn{1}{|c|}{$88.36 \pm 6.57$} \\
\hline Peak systolic velocity (cm/s) & $41.89 \pm 13.13$ \\
\hline Second peak velocity (cm/s) & $20.63 \pm 8.97$ \\
\hline End diastolic velocity (cm/s) & $9.29 \pm 5.13$ \\
\hline Time-average maximum velocity (cm/s) & $17.34 \pm 7.31$ \\
\hline Pulsatility index & $1.97 \pm 0.53$ \\
\hline Resistive index & $0.78 \pm 0.07$ \\
\hline Peak ratio (second peak velocity $\div$ peak systolic velocity) & $0.49 \pm 0.12$ \\
\hline \multicolumn{1}{|c|}{ Optic nerve sheath variables } & $4.34 \pm 0.4$ \\
\hline Optic nerve sheath diameter (mean of two orthogonal planes) (mm) & \\
\hline
\end{tabular}

Table 2: Outcomes of antenatal ophthalmic sonography 


\begin{tabular}{|l|l|c|}
\hline \multirow{5}{*}{ Mean arterial pressure } & Ophthalmic artery peak ratio & 0.653 \\
\cline { 2 - 3 } & Ophthalmic artery pulsatility index & 0.227 \\
\cline { 2 - 3 } & Ophthalmic artery peak systolic velocity & 0.915 \\
\cline { 2 - 3 } & Optic nerve sheath diameter & 0.606 \\
\hline \multirow{5}{*}{ Gestation } & Ophthalmic artery peak ratio & 0.2 \\
\cline { 2 - 3 } & Ophthalmic artery pulsatility index & 0.471 \\
\cline { 2 - 3 } & Ophthalmic artery peak systolic velocity & 0.88 \\
\cline { 2 - 3 } & Optic nerve sheath diameter & 0.349 \\
\hline \multirow{5}{*}{ Optic nerve sheath diameter } & Ophthalmic artery pulsatility index & 0.66 \\
\cline { 2 - 3 } & Ophthalmic artery peak ratio & 0.45 \\
\hline
\end{tabular}

Table 3: Relationship between mean arterial pressure, gestation, and various sonographic variables. 


\begin{tabular}{|l|c|c|c|}
\hline \multicolumn{1}{|c|}{$\mathbf{N}=\mathbf{2 1}$} & Mean \pm SD & $\begin{array}{c}\text { Difference in mean } \\
\text { from antenatal exam } \\
\text { (95\% CI) }\end{array}$ & p \\
\hline $\begin{array}{l}\text { Interval between delivery and examination } \\
\text { (hours) }\end{array}$ & $31.27 \pm 19.19$ & \multicolumn{2}{|c|}{0.55} \\
\hline Mean arterial pressure (mmHg) & $89.35 \pm 6.29$ & $+0.99(-1.7,+3.68)$ & 0.72 \\
\hline \multicolumn{1}{|c|}{ Ophthalmic artery Doppler variables } & 0.68 \\
\hline Peak systolic velocity (cm/s) & $40.72 \pm 11.09$ & $-1.17(-5.91,+3.57)$ & $\mathbf{0 . 0 0 0 1}$ \\
\hline Second peak velocity (cm/s) & $19.89 \pm 5.99$ & $-0.74(-3.3,+1.82)$ & $\mathbf{0 . 0 3 7}$ \\
\hline End diastolic velocity (cm/sc) & $5.73 \pm 2.30$ & $-3.56(-4.54,-2.58)$ & 0.99 \\
\hline $\begin{array}{l}\text { Time-average maximum velocity (cm/s) } \\
\text { Pulsatility index }\end{array}$ & $14.32 \pm 4.4$ & $-3.02(-4.9,-1.14)$ & $\mathbf{0 . 0 0 0 7}$ \\
\hline $\begin{array}{l}\text { Resistive index } \\
\text { Orthogonal planes) (mm) }\end{array}$ & $2.50 \pm 0.56$ & $+0.53(+0.29,+0.77)$ & $\mathbf{0 . 0 0 0 1}$ \\
\hline Systolic velocity) & $0.85 \pm 0.06$ & $+0.07(+0.045,+0.095)$ & 0.96 \\
\hline
\end{tabular}

Table 4: Outcomes of postnatal ophthalmic sonography

This article is protected by copyright. All rights reserved. 


\begin{tabular}{|c|c|c|c|c|c|c|c|c|}
\hline & $\begin{array}{l}\text { Mean } \\
\text { value }\end{array}$ & $\begin{array}{c}\text { Mean } \\
\text { difference }\end{array}$ & $\begin{array}{c}95 \% \\
\text { CI }\end{array}$ & $\begin{array}{c}\text { Correlation } \\
\text { coefficient } \\
(r)\end{array}$ & $\begin{array}{c}\text { Lower } \\
\text { limit of } \\
\text { agreement }\end{array}$ & $95 \%$ CI & $\begin{array}{c}\text { Upper } \\
\text { limit of } \\
\text { agreement }\end{array}$ & 95\% CI \\
\hline \multicolumn{9}{|c|}{ Inter-reader } \\
\hline $\begin{array}{l}\text { Second } \\
\text { peak OA } \\
\text { velocity } \\
(\mathrm{cm} / \mathrm{s})\end{array}$ & 21.12 & 0.02 & $\begin{array}{l}-0.13, \\
0.17\end{array}$ & 0.997 & -1.26 & $\begin{array}{l}-1.52 \\
-1.00\end{array}$ & 1.3 & $\begin{array}{l}1.04, \\
1.56\end{array}$ \\
\hline $\begin{array}{l}\text { Optic nerve } \\
\text { sheath } \\
\text { diameter } \\
(\mathrm{mm})\end{array}$ & 4.48 & -0.27 & $\begin{array}{l}-0.36, \\
-0.19\end{array}$ & 0.795 & -0.97 & $\begin{array}{l}-1.11 \\
-0.83\end{array}$ & 0.42 & $\begin{array}{l}0.28 \\
0.56\end{array}$ \\
\hline \multicolumn{9}{|c|}{ Intra-reader } \\
\hline $\begin{array}{l}\text { Second } \\
\text { peak OA } \\
\text { velocity } \\
(\mathrm{cm} / \mathrm{s})\end{array}$ & 21.13 & 0.0003 & $\begin{array}{c}-0.10, \\
0.10\end{array}$ & 0.998 & -0.86 & $\begin{array}{l}-1.03 \\
-0.68\end{array}$ & 0.86 & $\begin{array}{l}0.68, \\
1.03\end{array}$ \\
\hline $\begin{array}{l}\text { Optic nerve } \\
\text { sheath } \\
\text { diameter } \\
(\mathrm{mm})\end{array}$ & 4.38 & -0.068 & $\begin{array}{l}-0.13, \\
-0.01\end{array}$ & 0.819 & -0.55 & $\begin{array}{c}-0.65,- \\
0.45\end{array}$ & 0.41 & $\begin{array}{l}0.32 \\
0.51\end{array}$ \\
\hline
\end{tabular}

Table 5: Summary of measures of inter- and intra-reader reliability. The mean value is the average of the two reader means (inter-reader) or two occasion means (intra-reader). 


\begin{tabular}{|c|c|c|c|c|c|}
\hline Study & $\begin{array}{c}\mathrm{N} \\
\text { (total) }\end{array}$ & $\begin{array}{c}\text { Gestation } \\
\text { (weeks) } \\
\text { Range or } \\
\text { mean } \pm \text { SD }\end{array}$ & $\begin{array}{l}\text { Mean PI } \\
\quad \pm \text { SD }\end{array}$ & $\begin{array}{l}\text { Mean RI } \\
\quad \pm \text { SD }\end{array}$ & $\begin{array}{l}\text { Mean PR } \\
\quad \pm \text { SD }\end{array}$ \\
\hline $\begin{array}{l}\text { Nakatsuka, et al. }{ }^{37} \\
\text { (Japan) }\end{array}$ & 10 & $27+$ & $2.33 \pm 0.44$ & $0.836 \pm 0.051$ & $0.434 \pm 0.08$ \\
\hline $\begin{array}{l}\text { Belfort, et al. }{ }^{39} \\
\text { (USA) }\end{array}$ & 10 & $37 \pm 3$ & $\mathrm{n} / \mathrm{a}$ & $0.70 \pm 0.06$ & $\mathrm{n} / \mathrm{a}$ \\
\hline Hata, et al. ${ }^{40}$ (Japan) & 14 & $37-40$ & $2.75 \pm 0.79$ & $\mathrm{n} / \mathrm{a}$ & $\mathrm{n} / \mathrm{a}$ \\
\hline Hata, et al. ${ }^{41}$ (Japan) & 15 & $30.9 \pm 8.1$ & $2.73 \pm 0.32$ & $\mathrm{n} / \mathrm{a}$ & $\mathrm{n} / \mathrm{a}$ \\
\hline $\begin{array}{l}\text { Hata and Miyazaki }{ }^{42} \\
\text { (Japan) }\end{array}$ & 16 & $38.6 \pm 1.2$ & $2.87 \pm 0.64$ & $\mathrm{n} / \mathrm{a}$ & $\mathrm{n} / \mathrm{a}$ \\
\hline Hata, et al. ${ }^{36}$ (Japan) & 17 & $16-40$ & $2.80 \pm 0.847$ & $\mathrm{n} / \mathrm{a}$ & $\mathrm{n} / \mathrm{a}$ \\
\hline $\begin{array}{l}\text { Belfort, et al. }{ }^{43} \\
\text { (USA) }\end{array}$ & 24 & $35 \pm 4$ & $\mathrm{n} / \mathrm{a}$ & $0.72 \pm 0.08$ & $\mathrm{n} / \mathrm{a}$ \\
\hline Hata, et al. ${ }^{44}$ (Japan) & 29 & $7-40$ & $2.92 \pm 0.59$ & $\mathrm{n} / \mathrm{a}$ & $\mathrm{n} / \mathrm{a}$ \\
\hline $\begin{array}{l}\text { Ayaz, et al. }{ }^{33} \\
\text { (Turkey) }\end{array}$ & 30 & $32+$ & $1.78 \pm 0.2$ & $0.78 \pm 0.03$ & $\mathrm{n} / \mathrm{a}$ \\
\hline $\begin{array}{l}\text { Takata, et al. }{ }^{38} \\
\text { (Japan) }\end{array}$ & 32 & $32.2 \pm 3.9$ & $2.11 \pm 0.39$ & $0.82 \pm 0.06$ & $0.47 \pm 0.07$ \\
\hline $\begin{array}{l}\text { Diniz, et al. }{ }^{45} \\
\text { (Brazil) }\end{array}$ & 51 & $30.2 \pm 5.7$ & $1.89 \pm 0.38$ & $0.78 \pm 0.05$ & $0.499 \pm 0.092$ \\
\hline $\begin{array}{l}\text { Melo, et al. }{ }^{46} \\
\text { (Brazil) }\end{array}$ & 60 & $35.8 \pm 2.7$ & $2.20 \pm 0.46$ & $0.81 \pm 0.07$ & $0.47 \pm 0.08$ \\
\hline $\begin{array}{l}\text { Correa-Silva, et al. }{ }^{21} \\
\text { (Brazil) }\end{array}$ & 63 & $19+$ & $\begin{array}{c}1.87 \pm 0.48 \\
\text { (right) } \\
1.86 \pm 0.46 \\
\text { (left) }\end{array}$ & $\begin{array}{c}0.76 \pm 0.08 \\
\text { (right) } \\
0.76 \pm 0.07 \\
\text { (left) }\end{array}$ & $\begin{array}{c}0.59 \pm 0.16 \\
\text { (right) } \\
0.58 \pm 0.16 \\
\text { (left) }\end{array}$ \\
\hline $\begin{array}{l}\text { Ohno, et al. }{ }^{32} \\
\text { (Japan) }\end{array}$ & 118 & $20-41$ & $1.14 \pm 0.21$ & $\mathrm{n} / \mathrm{a}$ & $\mathrm{n} / \mathrm{a}$ \\
\hline $\begin{array}{l}\text { MacKenzie, et al. }{ }^{31} \\
\text { (Canada) }\end{array}$ & 126 & $\begin{array}{l}28-32 \\
32-36 \\
36-41\end{array}$ & $\begin{array}{c}1.9 \pm 0.53 \\
1.75 \pm 0.4 \\
1.81 \pm 0.46\end{array}$ & $\begin{array}{l}0.74 \pm 0.07 \\
0.72 \pm 0.06 \\
0.72 \pm 0.06\end{array}$ & $\mathrm{n} / \mathrm{a}$ \\
\hline
\end{tabular}

This article is protected by copyright. All rights reserved. 


\begin{tabular}{|l|c|c|c|c|c|}
\hline $\begin{array}{l}\text { de Oliveira, et al. }{ }^{30} \\
\text { (Brazil) }\end{array}$ & 289 & $20-40$ & n/a & n/a & $\begin{array}{c}0.529 \pm 0.099 \\
\text { (right) } \\
0.555 \pm 0.095 \\
\text { (left) }\end{array}$ \\
\hline Present study & 50 & $27-40$ & $1.97 \pm 0.53$ & $0.78 \pm 0.07$ & $0.49 \pm 0.12$ \\
\hline
\end{tabular}

Table 6: Studies of ophthalmic artery Doppler variables in healthy pregnancies (adapted from de Oliveira et al. $2009^{30}$ ). SD = standard deviation, $\mathrm{PI}=$ pulsatility index, $\mathrm{RI}=$ resistive index, $\mathrm{PR}=$ peak ratio. 


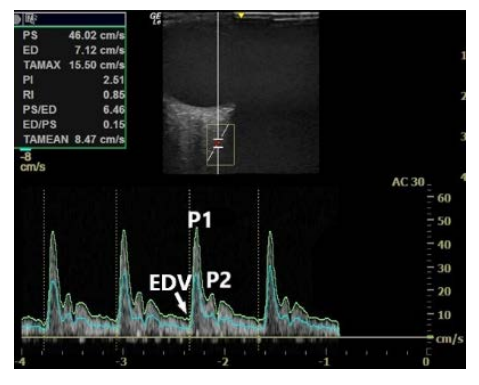




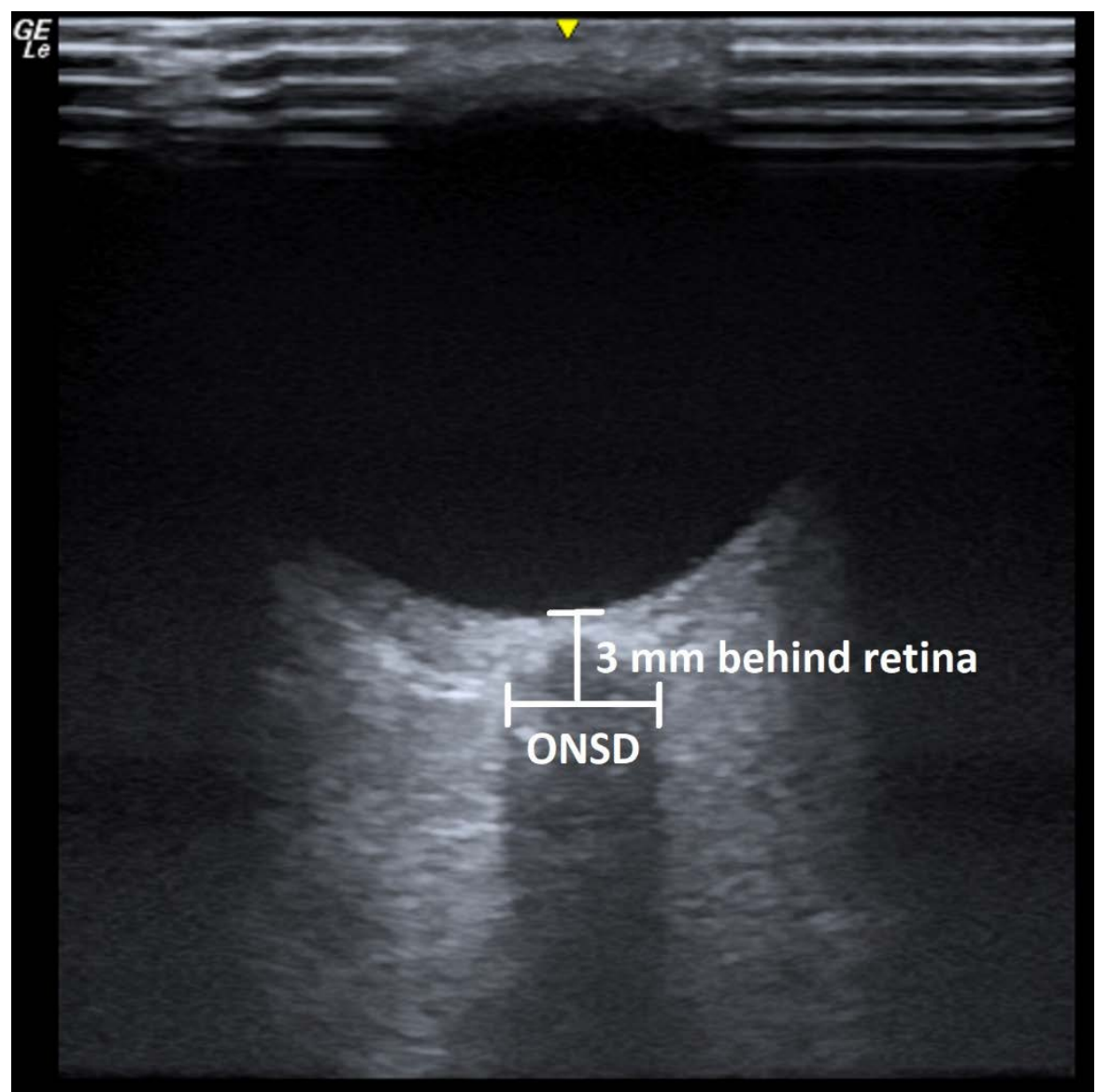




\begin{tabular}{|c|}
\hline \multicolumn{1}{|c|}{56 participants recruited to study } \\
\hline \\
\hline \\
\hline Antenatal sonographic examinations successfully performed on 53 participants \\
\hline \\
\hline 3 subsequently excluded from final cohort (1 with postnatal pre-eclampsia, 2 with preterm birth) \\
\hline 50 participants with uncomplicated term pregnancies with normally grown infants in final cohort \\
\hline \\
\hline 21 participants with uncomplicated vaginal births and available for postnatal assessment \\
\hline \\
\hline Total of 74 discrete examinations available for calculation of inter- and intra-reader reliability \\
\hline
\end{tabular}




\section{University Library}

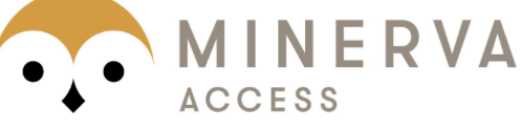

A gateway to Melbourne's research publications

Minerva Access is the Institutional Repository of The University of Melbourne

Author/s:

Kane, SC;Dennis, AT;Da Silva Costa, F;Kornman, LH;Cade, TJ;Brennecke, SP

Title:

Optic nerve sonography and ophthalmic artery Doppler velocimetry in healthy pregnant women: an Australian cohort study

Date:

2019-11-01

\section{Citation:}

Kane, S. C., Dennis, A. T., Da Silva Costa, F., Kornman, L. H., Cade, T. J. \& Brennecke, S. P. (2019). Optic nerve sonography and ophthalmic artery Doppler velocimetry in healthy pregnant women: an Australian cohort study. JOURNAL OF CLINICAL ULTRASOUND, 47 (9), pp.531-539. https://doi.org/10.1002/jcu.22735.

Persistent Link:

http://hdl.handle.net/11343/285863 